\title{
Do conspecific herbivores track resource depletion through host phenology-specific HIPVs?
}

\author{
P. D. Kamala Jayanthi ${ }^{1, *}$, Anjana Subramoniam ${ }^{1}$, P. Saravan Kumar ${ }^{1}$, \\ B. R. Jayanthimala ${ }^{1}$ and A. Rekha ${ }^{2}$ \\ ${ }^{1}$ Division of Entomology and Nematology, and \\ ${ }^{2}$ Division of Fruit Crops, ICAR-Indian Institute of Horticultural Research, Hessaraghatta Lake PO, Bengaluru 560 089, India
}

Conspecific herbivores use herbivore-induced plant volatiles (HIPVs) as cues while selecting an optimal site for oviposition. This is to ascertain the availability of nourishment for their progeny so that they get the best chance at survival. In the present study, phytophagous eulophid seed-borer Anselmella kerrichi was significantly (time spent: $F_{3,40}=13.12, P<0.0001$; number of entries: $F_{2,30}=4.21 ; P=0.02$ ) attracted to HIPVs from immature fruits of Java plum, Syzygium cuminii (time spent: $4.77 \pm 0.40 \mathrm{~min}$; number of entries: $2.27 \pm 0.24)$ when also given the choice of mature fruits (time spent: $1.76 \pm 0.32 \mathrm{~min}$; number of entries: $1.46 \pm 0.16)$, indicating that herbivores can assess resource depletion from host phenology-specific HIPVs. The chemical cues like $\alpha$-pinene, $\beta$-pinene, (z)-ocimene, undecane, 3,7-dimethyl decane, neo-alloocimene, allo-ocimene, ethyl benzoate, 2,6,11-trimethyldodecane, $\alpha$-copaene and $\beta$-caryophyllene, which are present in immature fruit volatiles elicited antennal response in a GC-EAD analysis. Olfactometer analyses with the synthetic compounds also revealed that A. kerrichi was significantly attracted to these cues and the synthetic blend composed of the above compounds proved to be much more efficient in attracting female wasps when compared to a natural blend. Field evaluations using the synthetic blend showed that it could attract a significant number of $A$. kerrichi, indicating the scope of using this blend of synthetic HIPVs as a sustainable IPM tool.

Keywords: Anselmella kerrichi, herbivore-induced plant volatiles, host phenology, resource depletion, Syzygium cuminii.

PLANTS upon being attacked by herbivores emit a number of distinct volatiles often known as herbivore-induced plant volatiles (HIPVs) that have multiple functions at different trophic levels ${ }^{1-5}$. From the plant's perspective, these HIPVs act as communication signals to attract natural enemies and alert various parts of same plant or neighbouring plants, thereby serving as a direct and indi-

\footnotetext{
*For correspondence. (e-mail: jaiinsect@gmail.com)
}

rect plant defence ${ }^{6}$. The role of HIPVs was studied in detail against a handful of insect pests, from the point of view of herbivores. However, the ecological function of HIPVs to conspecifics was found to be variable depending upon the herbivore species, thus making the community interactions quite complex. This emphasizes the need to understand and study the utilization of HIPVs by conspecifics on a case-by-case basis. Conspecific herbivores, particularly moths, are often repelled by the HIPVs produced by larval feeding as observed in Trichoplusia ni

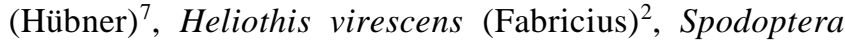
frugiperda (J.E. Smith) ${ }^{8}$, Manduca quinquemaculata (Haworth) and Manduca sexta (Linnaeus) ${ }^{9}$. On the contrary, HIPVs also serve as attractive cues to conspecifics as noticed in Colorado potato beetle, Leptinotarsa decemlineata (Say) ${ }^{10}$, Mamestra brassicae (Linnaeus), Spodoptera littoralis (Boisduval) ${ }^{11}$, leaf beetle, Oreina cacaliae $(\text { Schrank })^{12}$, Japanese beetles Popillia japonica New$\operatorname{man}^{13}$ and thrips, Scirtothrips dorsalis (Hood) ${ }^{5}$.

The herbivores that display attraction or repulsion to HIPVs produced by conspecifics must have their own interests. Herbivores which exhibit attraction have their interests in host location ${ }^{1,2,5}$, better fitness cost to progeny ${ }^{10,12,14}$, compromised host defence ${ }^{15}$, easy access to cohorts and mates ${ }^{10,12}$, avoidance of natural enemies due to clustering ${ }^{16}$ and attracting hyperparasitoids ${ }^{17-19}$. The herbivores which exhibit repulsion may also have their own advantages like reduction in competition for resources $^{2}$ to avoid attack of natural enemies ${ }^{3,4,20}$ in order to avoid poor nutrition status of the host plant due to induced defences ${ }^{10}$.

Thus, the varied behavioural responses of herbivores to HIPVs produced by conspecifics not only remain confusing, but also demand a case-by-case analysis as mentioned earlier. Host-plant phenology additionally performs a significant role in influencing the decision of herbivores in rejecting or accepting a host with conspecifics, as host phenology precisely defines the availability of food resources to their progeny. Particularly among short-lived herbivores whose progeny are mostly internal feeders, and cannot relocate on depletion of food resources, it becomes all the more important for the gravid females to 
synchronize their egg-laying with the appropriate stage of host phenology that maximizes the progeny fitness ${ }^{21}$.

Anselmella kerrichi (Narayanan, Subba Rao \& Patel), a short-lived phytophagous, eulophid wasp attacks immature fruits of jamun (Java plum), Syzygium cuminii Skeels (family Myrtaceae), causing extensive damage ${ }^{22}$. Upon oviposition in immature fruits, the emerging grubs tunnel down and reach the seed kernel. They feed on the seed tissue and develop as well as pupate within it. The emerging adult wasps burrow out of the fruit through its epicarp, making numerous exit holes on the surface, thereby affecting the fruit quality ${ }^{22}$. The present study was conducted to understand the response of jamun seed borer, $A$. kerrichi to HIPVs produced from different host fruit phenological stages damaged by conspecifics.

\section{Materials and methods}

\section{Insect collection}

The eulophid wasp-infested fruits were collected from the field in ICAR-Indian Institute of Horticultural Research, Bengaluru $\left(13.1348^{\circ} \mathrm{N}, 77.4960^{\circ} \mathrm{E}\right)$ during March 2019 and placed in plastic containers $(15 \times 12 \times 20 \mathrm{~cm})$ for wasp emergence. The emerged insects were allowed to mate and collected in separate plastic vials $(5 \times 2 \times 2 \mathrm{~cm})$ for performing both olfactometer assays as well as coupled gas chromatography-electroantennodetection (GCEAD) studies. The male and female insects were differentiated on the basis of abdomen size.

\section{Chemicals}

Authentic chemical standards ( $>95 \%$ purity) of $\alpha$-pinene (97\%), $\beta$-pinene (97\%), (z)-ocimene (>90\%), undecane (>99\%), allo-ocimene ( $80 \%$ technical grade), ethyl benzoate $(>99 \%)$ and $\beta$-caryophyllene $(>80 \%)$ were purchased from Sigma Aldrich. The remaining chemicals for which no standards are commercially available were identified through NIST spectral library 14.

\section{Air entrainment collection}

Headspace samples of wasp-infested immature and mature jamun fruits (cv. Dhupdal, $n=25$ ) were collected by air entrainment method according to the procedure described earlier ${ }^{23}$. The fruit traits namely size, colour, softness of berries were considered to assess fruit maturi$\mathrm{ty}^{22}$. Both the immature (small green and hard berries) and mature (large, purple soft berries) bunches infested by wasps were detached from the tree using secateurs, placed in polythene covers with minimal disturbance and brought to the laboratory for collection of volatiles. Fruit bunches were placed inside a round-bottomed glass con- tainer (10 cm height; $8 \mathrm{~cm}$ diameter) covered with a glass lid (with inlet and outlet ports on top) with flanges to seal it airtight. Purified air was pushed and pulled through the inlet and outlet ports respectively, according to the procedure described earlier ${ }^{23}$. The volatiles were entrained for $24 \mathrm{~h}$ into the odour cartridges made up of adsorbent, Porapak Q (50 mg, 60/80 mesh; Supelco, Sigma, India). The cartridges were eluted into the glass vials using $800 \mu$ redistilled diethyl ether; this served as the test sample of fruit volatiles. An internal standard of $500 \mathrm{ng} / \mu \mathrm{l}$ of $n$-pentadecane (99\% Pure, Sigma-Aldrich, India) was added to the extract for chemical quantification $^{24}$. Volatile samples were stored in a freezer $\left(-20^{\circ} \mathrm{C}\right)$ until further use.

\section{Olfactometer bioassays}

Single- and dual-choice olfactometer bioassays were carried out to measure the behavioural response of $A$. kerrichi females to headspace samples of immature and mature fruit volatiles as well as synthetic standards and synthetic volatile blends, according to the procedure described by Kamala Jayanthi et al. ${ }^{23}$ using a Perspex fourarm olfactometer $\left(120 \mathrm{~mm}\right.$ diameter ${ }^{25}$. Data on the time spent and number of entries made by $A$. kerrichi female into each arm were recorded using OLFA software (F. Nazzi, Udine, Italy) across the assays. Initially singlechoice assays were performed, where the insects were tested with immature and mature jamun volatiles individually against solvent control $(n=12)$. Later a dual-choice assay was performed, where both the fruit volatiles were offered to the female wasps along with solvent control to identify the most preferred sample. Secondly, the response of insects to synthetic compounds (identified from the most preferred sample) that elicited antennal response during GC-EAD was tested individually against solvent control $(n=12)$. Among these compounds only the ones that are commercially available were tested in the olfactometer bioassays. Thirdly, a dual-choice assay was performed to compare the synthetic blend (that contained GC-EAD responded and identified compounds at the same concentration and ratio as the headspace sample) with the natural headspace sample $(n=12)$. The data of single-choice assays were subjected to paired $t$-test and those of dual-choice assays were subjected to one-way ANOVA with Bonferroni multiple comparisons using GraphPad Prism (ver. 7.03).

\section{Coupled gas chromatography-electroantenno- detection}

The GC-EAD recordings were made according to the procedure described earlier ${ }^{23}$. The insects were starved for $2 \mathrm{~h}$ before conducting the experiment and the head of a mated female $A$. kerrichi $(n=6)$ anaesthetized by chilling, 
was separated from the body with a microscalpel and placed between the indifferent and the recording electrodes. The Porapak Q elutes collected in a solvent (DEE, diethyl ether, Merck, 99.97\%) were analysed on a GC system (Agilent 7890B GC) equipped with a flame ionization detector (FID) and a non-polar HP-5 column bonded phase fused silica capillary column $(30 \mathrm{~m}$ length $\times 0.250 \mathrm{~mm}$ diameter $\times 0.25 \mu \mathrm{m}$ thickness). The thermal programme was set initially at an oven temperature of $60^{\circ} \mathrm{C}$ for $1 \mathrm{~min}$, and then ramped at $15^{\circ} \mathrm{C} / \mathrm{min}$ to $240^{\circ} \mathrm{C}$ held for $2 \mathrm{~min}$ at pressure $8.2995 \mathrm{psi}$ on split-less mode $(40 \mathrm{ml} / \mathrm{min})$. Injector and detector temperatures were $250^{\circ} \mathrm{C}$ and $300^{\circ} \mathrm{C}$ respectively. Nitrogen was used as the carrier gas at constant flow of $1 \mathrm{ml} / \mathrm{min}$.

For coupled GC-EAD analysis, the effluent from GC column was split into two parts in the ratio $1: 1$, and each part was simultaneously directed to the GC detector and the antennal preparation through a heated $\left(250^{\circ} \mathrm{C}\right)$ transfer line. The electrode was connected to a high impedance DC amplifier (IDAC-4; Syntech). Compounds eluting from the GC column were delivered to the antenna through a glass tube $(12 \times 0.8 \mathrm{~cm})$, carried by a humidified and purified supplemental airflow at $200 \mathrm{ml} / \mathrm{min}$. The antennal and FID signals were simultaneously recorded and analysed using a customized software package (Syntech, Germany). Peaks eluting from the GC column were considered to be active if they elicited EAG activity in three or more of the six coupled runs carried out.

\section{Gas-chromatography coupled mass spectrometry analysis}

Chemical composition of Porapak Q elutes was analysed using GC-MS (Agilent 7890B GC) system equipped with mass spectrophotometry (Agilent 5977 MSD). A capillary column, (HP-5 MS UI) of $30 \mathrm{~m}$ length, $0.250 \mathrm{~mm}$ diameter and $0.25 \mu \mathrm{m}$ film thickness (Agilent $\mathrm{J} \& \mathrm{~W}$ ) was used to examine the samples. The oven temperature was set as described previously for the GC system. MS was in full scan mode $(70 \mathrm{eV})$ and amu ranged from 40 to 450 . One microlitre of the sample was injected in split-less mode $(40 \mathrm{ml} / \mathrm{min})$ with injection temperature at $270^{\circ} \mathrm{C}$. Helium was used as the carrier gas at a flow rate of $1 \mathrm{ml} / \mathrm{min}$. Individual volatile compounds were identified by comparing the $\mathrm{GC}$ retention time, Kovats index calculated using homologous series of $n$-alkanes (C7 to C30 procured from Sigma-Aldrich, India) as standard ${ }^{26}$ and comparing the MS spectra with NIST 14 spectral library. Identified EAD compounds were authenticated by coinjecting standard synthetic compounds along with samples. The relative abundance of each compound was calculated based on the internal standard ( $n$-pentadecane) within the sample. A heat map was plotted for comparing the GC-MS-identified compounds using GraphPad Prism software (ver. 7.0).

\section{Studies with synthetic HIPVs}

The pure-grade chemicals of seven compounds that are found significantly attractive to A. kerrichi in the olfactometer assays, namely $\alpha$-pinene, $\beta$-pinene, $(z)$-ocimene, undecane, allo-ocimene, ethyl benzoate and $\beta$-caryophyllene were made into a synthetic blend similar to natural headspace sample concentration as identified through GC-MS. The synthetic blend of all authentic standards, ethyl benzoate $(5.44 \mu \mathrm{g} / \mathrm{ml}), \quad \beta$-pinene $(47.50 \mu \mathrm{g} / \mathrm{ml})$, allo-ocimene $(83.24 \mu \mathrm{g} / \mathrm{ml})$, undecane $(196.30 \mu \mathrm{g} / \mathrm{ml})$, (z)-ocimene $(23.40 \mu \mathrm{g} / \mathrm{ml})$ and $\alpha$-pinene $(76.5 \mu \mathrm{g} / \mathrm{ml})$ was prepared with hexane (99.9\%, Sigma-Aldrich, USA). The blend was used in bioassays as well as in A. kerrichi field-trapping studies. Also, $250 \mu \mathrm{l}$ of synthetic blend filled into 50-gauge PE (polyethylene) sachets of dimensions $24 \mathrm{~cm}^{2}$ served as lures for field studies.

\section{Field trapping}

To test the attraction of the synthetic lure, the PE sachets prepared were stuck to white A4-sized sticky traps $(29 \mathrm{~cm} \times 11 \mathrm{~cm})$. These traps were randomly hung on the branches of jamun trees at $2 \mathrm{~m}$ above the ground. Data on the numbers of $A$. kerrichi trapped were collected daily over a week. The white sticky traps without PE sachets served as control and were placed on separate trees. The experiment was replicated thrice and data were subjected to a non-parametric Mann-Whitney $U$ test (unpaired; $\alpha=0.05$ ) using GraphPad Prism (ver. 7.0).

\section{Results}

In the present study, the gravid female eulophid wasps, did not exhibit any preference to spend time $(P=0.12)$ in the region treated with mature fruit HIPVs (1.79 \pm $0.17 \mathrm{~min})$ compared to the control $(2.40 \pm 0.24)$. However, they made a significantly greater number of entries $(P=0.02)$ into the arm $(2.75 \pm 0.28)$ treated with mature fruit HIPVs compared to the control arm $(1.89 \pm 0.25)$. The female wasps spent significantly more time (4.68 \pm $0.41 \mathrm{~min}$ in the treated arm; $2.45 \pm 0.88 \mathrm{~min}$ in control arm; $P=0.03$ ) and made significantly more entries $(2.58 \pm 0.19$ in the treatment arm; $1.75 \pm 0.14$ in control arm; $P=0.002)$ into the treatment arm containing immature fruit HIPVs over the control (Figure 1).

In the dual-choice assay, when both the immature and mature fruit HIPVs were presented, the female A. kerrichi wasps spent significantly more time $\left(F_{3,40}=13.12\right.$, $P<0.0001)$ in the region treated with immature fruit HIPVs $(4.77 \pm 0.40 \mathrm{~min})$ over mature fruit HIPVs $(1.76 \pm 0.32 \mathrm{~min})$ and the control regions (control 1; $1.87 \pm 0.45 \mathrm{~min}$; control 2: $2.03 \pm 0.42 \mathrm{~min})$. Similar trend was observed for the number of entries made by female wasps, where a significantly greater number of 

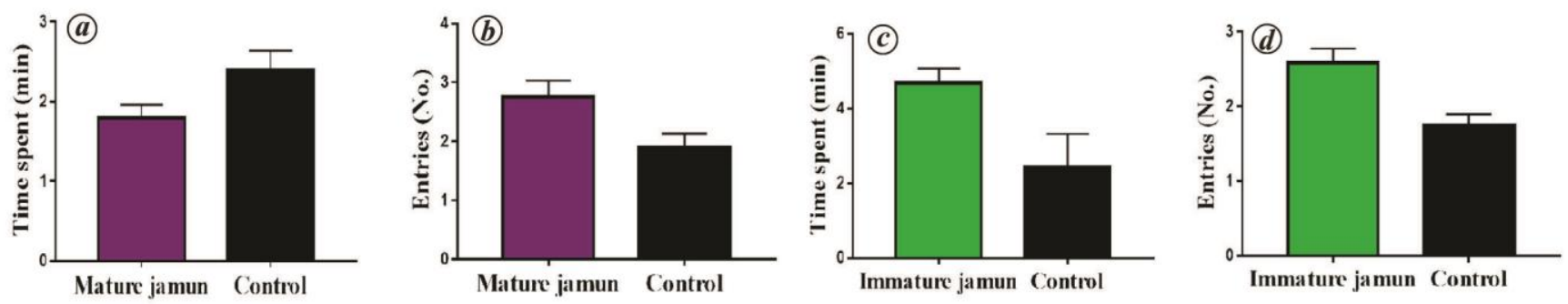

Figure 1. Behavioural response of female Anselmella kerrichi to volatiles collected from infested mature $(\boldsymbol{a}, \boldsymbol{b})$ and immature fruits $(\boldsymbol{c}, \boldsymbol{d})$ of jamun, Syzygium cuminii $(n=12)$. $\boldsymbol{a}$, Time spent by the wasps did not differ significantly between the mature fruit volatiles and control $(P=\mathrm{NS})$. $\boldsymbol{b}$, Wasps made a significantly greater number of entries into mature fruit volatiles-treated region over control $(P=0.02)$. $\boldsymbol{c}$, Time spent by the wasps differed significantly between immature fruit volatiles and control $(P=0.03)$. $\boldsymbol{d}$, Wasps made a significantly greater number of entries into the immature fruit volatiles-treated region over control $(P=0.002)$.
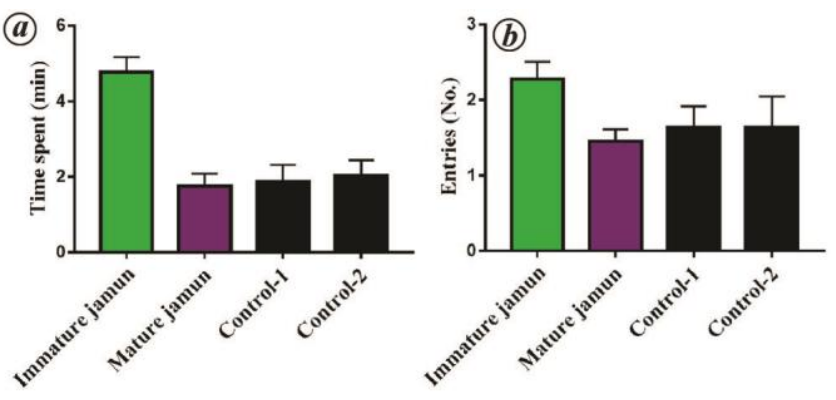

Figure 2. Dual-choice assay showing the behavioural response of $A$ kerrichi to volatiles collected from infested immature and mature fruits of jamun. $\boldsymbol{a}$, Wasps spent significantly more time $(P<0.0001)$. $\boldsymbol{b}$, Wasps made significantly greater number of entries in immature fruit volatiles treated region compared to other treatments $(P=0.02)$.

entries $\left(F_{2,30}=4.21 ; P=0.02\right)$ were made into the immature fruit HIPVs-treated region $(2.27 \pm 0.24)$ compared to the regions treated with mature fruit HIPVs $(1.46 \pm 0.16)$ and the controls (control 1: $1.64 \pm 0.23$; control 2: $1.64 \pm 0.41)$ (Figure 2).

Heat-map analysis of GC-MS data of both the immature and mature fruit HIPVs revealed distinct differences in the volatile profile emissions (Figure 3) (Supplementary Table 1). The main volatile components: monoterpenes, namely $\alpha$-pinene $(76.53 \mu \mathrm{g} / \mathrm{ml}, 37.3 \mu \mathrm{g} / \mathrm{ml}), \quad \beta$-pinene $(47.5 \mu \mathrm{g} / \mathrm{ml}, 33.2 \mu \mathrm{g} / \mathrm{ml})$ and allo-ocimene $(83.24 \mu \mathrm{g} / \mathrm{ml}$, $7.6 \mu \mathrm{g} / \mathrm{ml})$ were found to vary significantly $(P=0.05)$ between the immature and mature jamun fruit volatiles respectively. Compounds like 3,7-octadiene-2,6-diol, 2,6dimethyl $(10.56 \mu \mathrm{g} / \mathrm{ml})$, 3-carene $(15.62 \mu \mathrm{g} / \mathrm{ml})$, neoallo-ocimene $\quad(42.41 \mu \mathrm{g} / \mathrm{ml}), \quad \alpha$-pyronene $(8.58 \mu \mathrm{g} /$ $\mathrm{ml})$ and elixene $(10.27 \mu \mathrm{g} / \mathrm{ml})$ were exclusively found in immature fruit volatiles and completely absent in mature fruit volatiles, while compounds such as $\beta$-myrcene $(24.2 \mu \mathrm{g} / \mathrm{ml})$, limonene $(5.21 \mu \mathrm{g} / \mathrm{ml})$, trans- $\beta$-ocimene $(52.1 \mu \mathrm{g} / \mathrm{ml})$, linalool oxide $(12.2 \mu \mathrm{g} / \mathrm{ml})$, trans-linalool oxide (furanoid; $10.8 \mu \mathrm{g} / \mathrm{ml}$ ) and caryophyllene oxide $(8.60 \mu \mathrm{g} / \mathrm{ml})$ were found only in mature fruit volatiles and completely absent in immature fruit volatiles.

The acyclic monoterpenoid, 1,3,7-nonatriene, 4,8dimethyl-, (3E) $(38.6 \mu \mathrm{g} / \mathrm{ml})$ and phenol group containing compounds like methylguaiacol $(81.9 \mu \mathrm{g} / \mathrm{ml})$ were exclusively found in mature fruit volatiles and completely absent in immature fruit volatiles. Aldehydes such as decanal $(4.4 \mu \mathrm{g} / \mathrm{ml})$ and $n$-heptanal $(4.26 \mu \mathrm{g} / \mathrm{ml})$ were present only in mature fruit volatiles, while ethyl-benzaldehyde $(5.93 \mu \mathrm{g} / \mathrm{ml})$ and cis-5-methyl-2-isopropyl-2hexene-1-al $(1.23 \mu \mathrm{g} / \mathrm{ml})$ were present only in immature fruit volatiles and not present in mature fruit volatiles. The esters/acids such as ethyl benzoate, methyl salicylate, 1,2,4-benzenetricarboxylic acid, and 1,2-dimethyl ester were found significantly $(P=0.05)$ in higher concentrations $(342.9,79.7$ and $1.31 \mu \mathrm{g} / \mathrm{ml})$ in mature fruit volatiles compared to the immature fruit volatiles $(5.44,5.5$ and $0.31 \mu \mathrm{g} / \mathrm{ml})$. Compounds such as benzoic acid, 4-ethoxy-, ethyl ester $(6.73 \mu \mathrm{g} / \mathrm{ml})$, acetic acid, oxo ((1phenylethyl) amino)-, hydrazide $(1.90 \mu \mathrm{g} / \mathrm{ml})$ were exclusively present in mature fruit volatiles and completely absent in immature fruit volatiles, whereas ethyl $p$ ethoxybenzoate $(27.05 \mu \mathrm{g} / \mathrm{ml})$ was found only in immature fruit volatiles and completely absent in mature fruit volatiles.

$O$-decylhydroxylamine $(3.50 \mu \mathrm{g} / \mathrm{ml})$, an amine groupcontaining compound and 3-ethylacetophenone $(6.61 \mu \mathrm{g} /$ $\mathrm{ml}$ ) were found only in immature fruit volatiles and completely absent in mature fruit volatiles. Similarly, acetophenones like $p$-acetylbenzene $(8.70 \mu \mathrm{g} / \mathrm{ml})$ were found only in mature fruit volatiles and not in immature fruit volatiles.

The compounds of alkane group like $n$-undecane $(192.7, \quad 196.3 \mu \mathrm{g} / \mathrm{ml})$ and 2,6,11-trimethyldodecane $(39.50,72.10 \mu \mathrm{g} / \mathrm{ml})$ were predominantly found in both mature and immature fruit volatiles respectively. Compounds like 2,4,6-trimethyldecane $(27.2 \mu \mathrm{g} / \mathrm{ml})$, 2methyldodecane $(25.90 \mu \mathrm{g} / \mathrm{ml}), \quad$ 2-methyltetradecane (33.80 $\mu \mathrm{g} / \mathrm{ml}), 2,6,10$-trimethyltetradecane $(23.70 \mu \mathrm{g} / \mathrm{ml})$ and 7,7-diethylheptadecane $(1.50 \mu \mathrm{g} / \mathrm{ml})$ were exclusively found in mature fruit volatiles and completely absent in immature ones. Compounds like 2,5-dimethyl-2-undecene $(9.98 \mu \mathrm{g} / \mathrm{ml}), 3,7$-dimethyl decane $(198.95 \mu \mathrm{g} / \mathrm{ml})$, $n$-tetradecane $(3.75 \mu \mathrm{g} / \mathrm{ml}), n$-cetane $(43.83 \mu \mathrm{g} / \mathrm{ml})$, phytane $(9.63 \mu \mathrm{g} / \mathrm{ml})$ and 2,6,10,15-tetramethylheptadecane 


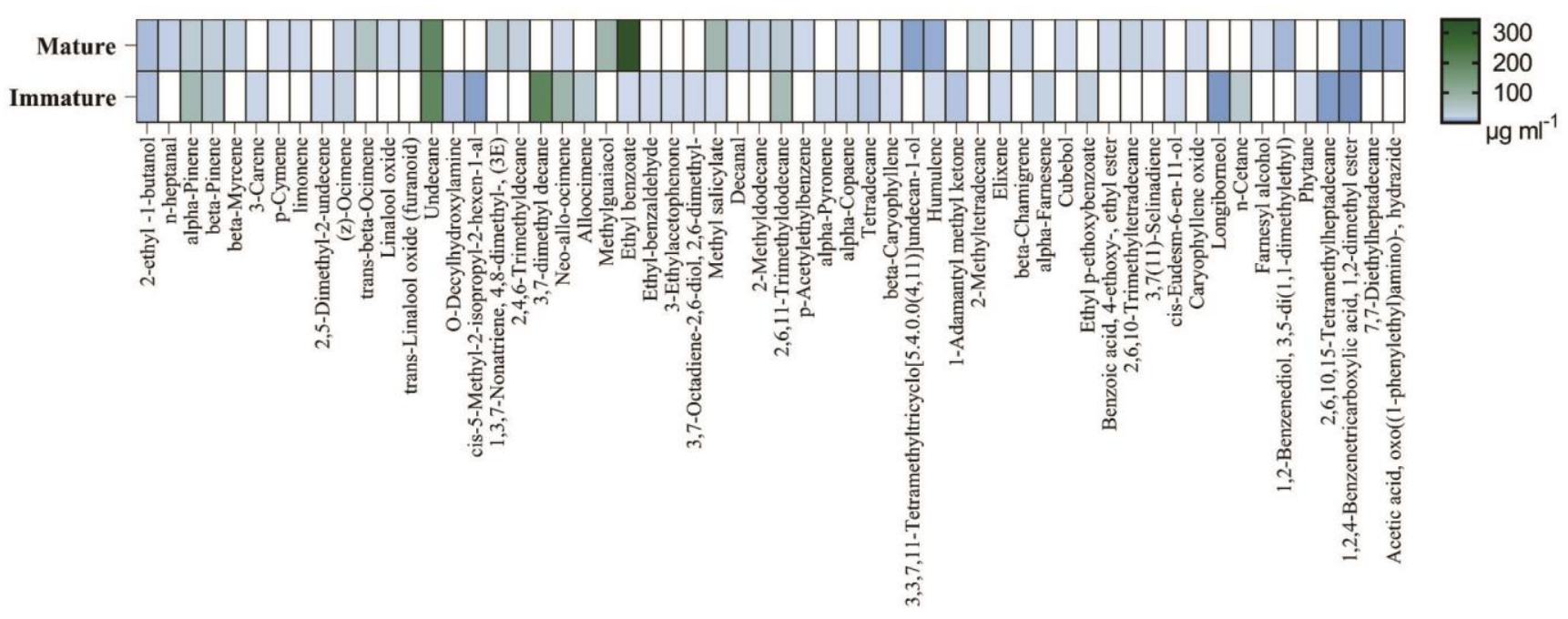

Figure 3. Heat map showing differences in the volatile emissions of infested mature and immature jamun fruits.

Table 1. Response of female Anselmella kerrichi to electrophysiologically active compounds (10 $\mu$ l) tested individually in a four-arm olfactometer bioassay $(n=12)$. Time spent and entries made by the female wasps into the treated regions were compared

\begin{tabular}{|c|c|c|c|c|c|c|}
\hline \multirow[b]{2}{*}{ Compound } & \multicolumn{2}{|c|}{$\begin{array}{l}\text { Time spent }(\min ) \\
\text { Mean } \pm \text { SE }\end{array}$} & \multirow[b]{2}{*}{$P$-value $(t$-test) } & \multicolumn{2}{|c|}{$\begin{array}{l}\text { Entries (number) } \\
\text { Mean } \pm \text { SE }\end{array}$} & \multirow[b]{2}{*}{$P$-value ( $t$-test) } \\
\hline & Treatment & Control & & Treatment & Control & \\
\hline$\alpha$-Pinene & $6.52 \pm 0.43$ & $1.06 \pm 0.21$ & $<0.0001$ & $1.67 \pm 0.19$ & $0.94 \pm 0.11$ & 0.002 \\
\hline$\beta$-Pinene & $5.44 \pm 0.40$ & $1.51 \pm 0.13$ & $<0.0001$ & $2.50 \pm 0.22$ & $1.77 \pm 0.17$ & 0.02 \\
\hline (z)-Ocimene & $3.45 \pm 0.40$ & $2.06 \pm 0.17$ & 0.01 & $1.67 \pm 0.14$ & $1.31 \pm 0.39$ & 0.02 \\
\hline Undecane & $5.93 \pm 0.68$ & $1.33 \pm 0.27$ & 0.0002 & $1.58 \pm 0.63$ & $0.86 \pm 0.14$ & 0.01 \\
\hline Allo-ocimene & $4.56 \pm 0.69$ & $2.16 \pm 0.80$ & 0.005 & $1.90 \pm 0.34$ & $1.42 \pm 0.25$ & 0.005 \\
\hline Ethyl benzoate & $5.24 \pm 0.89$ & $1.39 \pm 0.30$ & 0.003 & $2.42 \pm 0.31$ & $1.14 \pm 0.30$ & 0.004 \\
\hline$\beta$-Caryophyllene & $2.02 \pm 0.34$ & $2.55 \pm 0.24$ & 0.26 & $2.60 \pm 0.31$ & $1.90 \pm 0.29$ & 0.07 \\
\hline
\end{tabular}

$(0.92 \mu \mathrm{g} / \mathrm{ml})$ were only found in immature fruit volatiles and completely absent in mature fruit volatiles.

Alcohol-group containing compounds like cubebol $(8.70 \mu \mathrm{g} / \mathrm{ml})$, farnesyl alcohol $(6.10 \mu \mathrm{g} / \mathrm{ml}), 3,3,7,11$ tetramethyltricyclo $[5.4 .0 .0(4,11)]$ undecan-1-ol $(1.30 \mu \mathrm{g} /$ $\mathrm{ml}$ ) and 1,2-benzenediol, 3,5-di (1,1-dimethylethyl) $(2.70 \mu \mathrm{g} / \mathrm{ml})$ were exclusively found in mature fruit volatiles and not in immature fruit volatiles. Whereas cis-eudesm-6-en-11-ol $(5.26 \mu \mathrm{g} / \mathrm{ml})$ and longiborneol $(0.61 \mu \mathrm{g} / \mathrm{ml})$ were present only in immature fruit volatiles and absent in mature fruit volatiles. Additionally, 2-ethyl1-butanol $(3.10,3.25 \mu \mathrm{g} / \mathrm{ml})$ was found both in mature and immature fruit volatiles. Sesquiterpenes such as humulene $(2.10,6.0 \mu \mathrm{g} / \mathrm{ml}), \alpha$-copaene $(5.30,4.3 \mu \mathrm{g} / \mathrm{ml})$ and $\beta$-caryophyllene $(4.70,5.40 \mu \mathrm{g} / \mathrm{ml})$ were seen in both mature and immature fruit volatiles. $\alpha$-Farnesene $(24.63 \mu \mathrm{g} / \mathrm{ml})$ was found only in immature fruit volatiles and completely absent in mature fruit volatiles, $\beta$ chamigrene $(17.20 \mu \mathrm{g} / \mathrm{ml})$ and 3,7(11)-selinadiene $(7.70 \mu \mathrm{g} / \mathrm{ml})$ were found only in mature fruit volatiles and absent in immature fruit volatiles.
Ketone group-containing compound 1-adamantyl methyl ketone $(3.55 \mu \mathrm{g} / \mathrm{ml})$ was found to be present only in immature fruit volatiles and not in mature fruit volatiles. Whereas alkyl benzene, p-cymene $(5.80 \mu \mathrm{g} / \mathrm{ml})$ was found only in mature fruit volatiles and absent in immature fruit volatiles (Figure 3).

Coupled GC-EAD using female A. kerrichi antenna revealed eleven electrophysiologically active compounds, viz. $\alpha$-pinene, $\beta$-pinene, $(z$ )-ocimene, undecane, 3,7dimethyl decane, neo-allocimene, allo-ocimene, ethyl benzoate, 2,6,11-trimethyldodecane, $\alpha$-copaene, $\beta$ caryophyllene in the immature fruit HIPVs (Figure 4).

The four-arm olfactometer bioassays with individual synthetic compounds revealed that the female wasps spent significantly more time in the treated regions of synthetic compounds, namely ethyl benzoate, $\alpha$-pinene, $\beta$-pinene, $(z)$-ocimene, undecane, allo-ocimene and ethyl benzoate. Similar trend was noticed with the number of entries made by female wasps into the arm treated with synthetic compounds over respective control arms. Female wasps did not show any preference for $\beta$-caryophyllene 

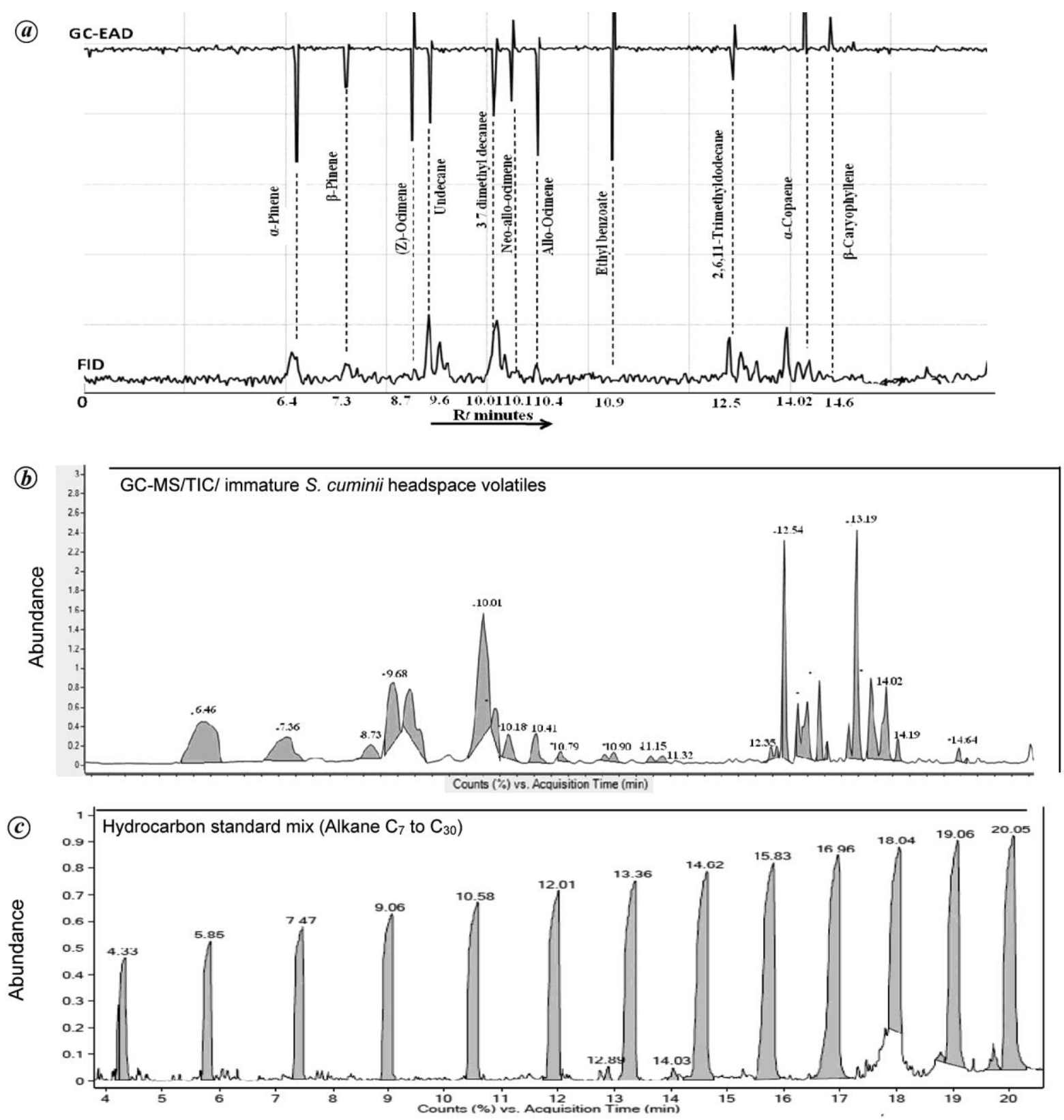

Figure 4. $\boldsymbol{a}$, Coupled gas chromatography-electroantennodetection (GC-EAD) trace of female A. kerrichi to headspace volatiles of immature jamun fruits, showing EAD-active compounds: $\alpha$-pinene (RI-937), $\beta$-pinene (RI-937), $(z)$-ocimene (RI-1038), undecane (RI-1100), 3,7-dimethyl decane (RI-1125), neo-allo-ocimene (RI-1131), allo-ocimene (RI-1131), ethyl benzoate (RI-1171), 2,6,11-trimethyldodecane (RI-1275), $\alpha$-copaene (RI1376); and $\beta$-caryophyllene (RI-1419). $\boldsymbol{b}$, gas-chromatography/mass spectrometry total ion chromatogram (GC/MS-TIC) of the headspace volatiles of immature jamun fruits. $c$, GC/MS-TIC of standard hydrocarbon mix, alkane $\left(\mathrm{C}_{7}\right.$ to $\left.\mathrm{C}_{30}\right)$.

either for time spent or entries made into the treated regions over control (Table 1). Due to the non-availability of compounds 3,7-dimethyl decane, neo-alloocimene and 2,6,11-trimethyldodecane, olfactometer bioassays for these were not carried out.

The gravid female eulophid wasps spent significantly more time $(P<0.0001)$ in the synthetic blend treated region $(6.03 \pm 1.31 \mathrm{~min})$ compared to the control $(1.57 \pm$ $0.41)$. The number of entries was also more in the treated region $(2.6 \pm 0.78 \mathrm{~min})$ compared to the control $(1.2 \pm$
0.39). In the dual-choice assay, when both the blends (synthetic and natural) were given, the female wasps spent significantly more time $\left(F_{3,36}=57.43, P<0.0001\right)$ in the synthetic blend-treated region $(6.69 \pm 0.24 \mathrm{~min})$ over natural blend $(3.23 \pm 0.53 \mathrm{~min})$ and the control regions (control 1: $1.81 \pm 0.33 \mathrm{~min}$; control 2: $0.66 \pm$ $0.18 \mathrm{~min}$ ). Similar trend was observed for the number of entries made by female wasps, where a significantly greater number of entries $\left(F_{3,36}=4.38 ; P=0.01\right)$ was noticed into the synthetic blend-treated region $(2.81 \pm 0.25)$ 
compared to the regions treated with natural blend $(2.01 \pm 0.33)$ and the controls (control 1: $1.70 \pm 0.52$; control 2: $1.00 \pm 0.26$ ) (Figure 5).

Field evaluations revealed a significant number of captures in the traps that contained synthetic blend as the lure (treatment $=2.86 \pm 0.73$; control $=0.05 \pm 0.05$; MannWhitney $U=73.50 ; P<0.0001)$ over control.

\section{Discussion}

Plant-produced HIPVs (when attacked by herbivores) are known to have multiple biological functions in herbivore-plant interactions involving conspecific/heterospecific herbivores, natural enemies, neighbouring plants and different parts within the damaged plant ${ }^{27}$. Therefore, HIPVs are considered to trigger multi-trophic interactions and also aid trophic relationships, supporting the fitness and survival of members representing diverse guilds ${ }^{27}$.

The response of conspecific herbivores to HIPVs remains confusing because of their contradictory behavioural responses to these volatiles. Earlier studies mention that the ovipositing herbivores prefer plants that do not emit HIPVs ${ }^{1}$. This might be due to the fact that early detection and avoidance of damaged plants by conspecifics have numerous benefits such as avoiding intra- or interspecific competitors ${ }^{28}$; heightened defence response in attacked plants ${ }^{29}$, higher parasitization and predation ${ }^{30}$. The HIPVs also attract conspecific herbivores for similar benefits like progeny fitness ${ }^{14}$, compromised plant defences ${ }^{15}$, avoiding natural enemies ${ }^{16}$ and finding mating
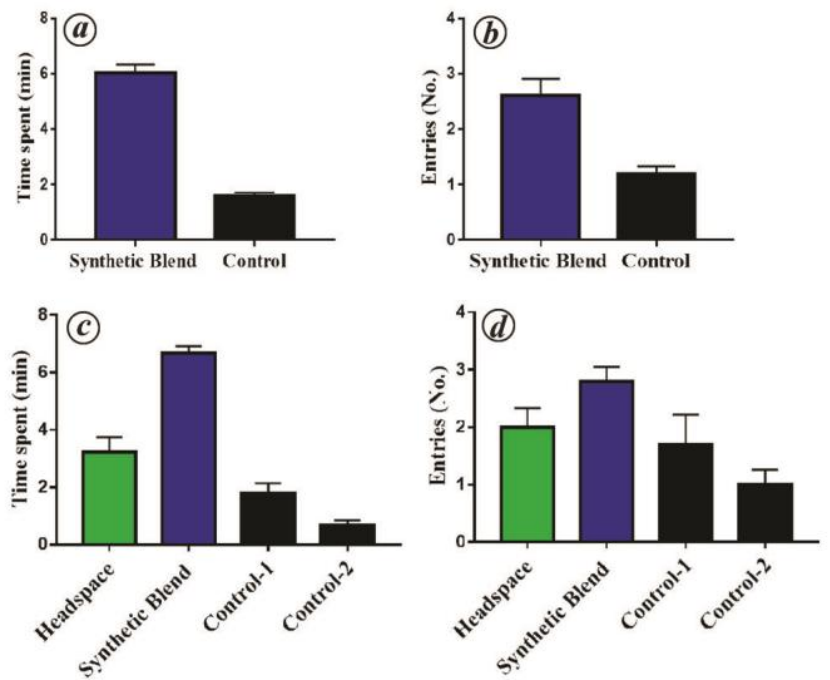

Figure 5. Single-choice assay showing the behavioural response of $A$. kerrichi to synthetic blend of infested immature jamun fruits. (a) Wasps spent significantly more time $(P<0.0001)$ and $(b)$ made significantly greater number of entries into regions treated with synthetic blend compared to other treatments $(P=0.01) . \boldsymbol{c}, \boldsymbol{d}$, Dual-choice assay showing the behavioural response of $A$. kerrichi to headspace sample collected from infested immature fruits of $S$. cuminii and its synthetic blend. partners ${ }^{10,12}$. Therefore, the role of HIPVs in the case of conspecific herbivores is puzzling as they have opposed roles like attraction ${ }^{5}$, and avoidance ${ }^{31}$, as the case may be, in the evolutionary context of their progeny fitness.

Egg-laying choice of female is always a trade-off between the immediate risk by natural enemies and availability of food resources ${ }^{32}$. The latter often becomes more important for egg-laying females as depletion of food resources impacts the survival of their progeny adversely when the mobility of immature stages is limited. In the present study, female wasps were attracted to HIPVs released from the immature fruits over mature fruits in single- and dual-choice bioassays. This may be due to the fact that female wasps can assess the quality of oviposition site in terms of food availability for their progeny. The gravid A. kerrichi wasps usually oviposit into the greenish immature fruits of $S$. cuminii. The emerging grubs of $A$. kerrichi tunnel through the pulp and reach the seed kernels. They feed exclusively on the seed kernel tissue forming a gall-like shell case and pupate within the seed $^{33}$. The mature, ripe fruits of $S$. cuminii are deep purple in colour and cannot be retained on the tree for long (http://agritech.tnau.ac.in/horticulture/horti_fruits_jamun. html). Thus, the female A. kerrichi would have sensed the unsuitable phenological stage of the host fruit through HIPVs of the mature fruits and would have avoided them as the eggs laid by wasps will have a better chance at reaching adulthood in immature fruits and the wasp grubs will have time to develop and close into adults. Similar behaviour was observed in Pieris brassicae, where gravid females were observed to assess resource depletion in terms of future quantity and/or quality potential of food plants to their progeny while making their egg-laying choice $^{33}$.

The heat-map analysis of HIPVs released from immature and mature fruit stages of $S$. cuminii differed significantly in their volatile composition both qualitatively and quantitatively, indicating these differences might be perceived by the gravid female wasps while choosing their egg-laying sites. The synthetic GC-EAD active compounds, namely ethyl benzoate, $\alpha$-pinene, $\beta$-pinene, (z)-ocimene, undecane, allo-ocimene, and ethyl benzoate could attract female wasps in olfactometer bioassays establishing their role in oviposition site selection of $A$. kerrichi. Further, the synthetic blend prepared from these active compounds could successfully attract the female wasps both in olfactometer assays as well as on the field.

\section{Conclusions}

The present study emphasizes that herbivores might assess the nutritional quality of an oviposition site based on HIPVs to reduce the risk of offspring losses. These HIPVs not only aid the herbivores regarding the compromised defences of host plant (=weak host) due to conspecifics, but also help the gravid females to track the 
resource depletion thereby impacting their oviposition site selection. The attraction of female A. kerrichi to synthetic HIPVs in the laboratory and field conditions ascertains the scope of using them as IPM tools for sustainable management of this phytophagous eulophid seed-borer.

1. Kessler, A. and Baldwin, I. T., Defensive function of herbivoreinduced plant volatile emissions in nature. Science, 2001, 291, 2141-2144.

2. De Moraes, C. M., Mescher, M. C. and Tumlinson, J. H., Caterpillar-induced nocturnal plant volatiles repel conspecific females. Nature, 2001, 410, 577-580.

3. Halitschke, R., Stenberg, J. A., Kessler, D., Kessler, A. and Baldwin, I. T., Shared signals: 'alarm calls' from plants increase apparency to herbivores and their enemies in nature. Ecol. Lett., 2008, 11, 24-34.

4. Degenhardt, J. et al., Restoring a maize root signal that attracts insect-killing nematodes to control a major pest. Proc. Natl. Acad. Sci. USA, 2009, 106, 13213-13218.

5. Shivaramu, S., Jayanthi, P. D. K., Kempraj, V., Anjinappa, R., Nandagopal, B. and Chakravarty, A. K., What signals do herbivore-induced plant volatiles provide conspecific herbivores? Arthropod-Plant Int., 2017, 11, 815-823.

6. Mitchell, C., Brennan, R. M., Graham, J. and Karley, A. J., Plant defense against herbivorous pests: exploiting resistance and tolerance traits for sustainable crop protection. Front. Plant Sci., 2016, 7, 1132.

7. Landolt, P. J., Effects of host plant leaf damage on cabbage looper moth attraction and oviposition. Entomol. Exp. Appl., 1993, 67, 79-85.

8. Signoretti, A., Penaflor, M., Moreira, L., Noronha, N. C. and Bento, J., Diurnal and nocturnal herbivore induction on maize elicit different innate response of the fall armyworm parasitoid, Campoletis flavicincta. Pestic. Sci., 2012, 85, 101-107.

9. Reisenman, C. E., Riffell, J. A., Duffy, K., Pesque, A., Mikles, D. and Goodwin, B., Species-specific effects of herbivory on the oviposition behavior of the moth Manduca sexta. J. Chem. Ecol., 2013, 39, 76-89.

10. Bolter, C. J., Dicke, M., van Loon, J. J. A., Visser, J. H. and Posthumus, M. A., Attraction of colorado potato beetle to herbivore-damaged plants during herbivory and after its termination. $J$. Chem. Ecol., 1997, 23, 1003-1023.

11. Anderson, P. and Alborn, H., Effects on oviposition behaviour and larval development of Spodoptera littoralis by herbivore induced changes in cotton plants. Entomol. Exp. Appl., 1999, 92, 45-51.

12. Kalberer, N. M., Turlings, T. C. J. and Rahier, M., Attraction of a leaf beetle (Oreina ca-caliae) to damaged host plants. J. Chem. Ecol., 2001, 27, 647-661.

13. Loughrin, J. H., Potter, D. A. and Hamiltonkemp, T. R., Attraction of Japanese beetles (Coleoptera, Scarabaeidae) to host plant volatiles in field trapping experiments. Environ. Entomol., 1998, 27, 395-400.

14. Williams, K. S. and Myers, J. H., Previous herbivore attack of red alder may improve food quality for fall webworm larvae. Oecologia, 1984, 63, 16-70.

15. Trowbridge, A. M., Daly, R. W., Helmig, D., Stoy, P. C. and Monson, R. K., Herbivory and climate interact serially to control monoterpene emissions from pinyon pine forests. Ecology, 2014, 95, 1591-1600.

16. Halitschke, R., Stenberg, J. A., Kessler, D., Kessler, A. and Baldwin, I. T., Shared signals: 'alarm calls' from plants increase apparency to herbivores and their enemies in nature. Ecol. Lett., 2008, 11, 24-34.
17. Mumm, R. and Dicke, M., Variation in natural plant products and the attraction of bodyguards involved in indirect plant defense. Can. J. Zool., 2010, 88, 627-667.

18. Dicke, M., van Loon, J. J. and Soler, R., Chemical complexity of volatiles from plants induced by multiple attack. Nat. Chem. Biol., 2009, 5, 317.

19. Cusumano, A., Harvey, J. A., Dicke, M. and Poelman, E. H., Hyperparasitoids exploit herbivore-induced plant volatiles during host location to assess host quality and non-host identity. Oecologica, 2019, 189, 699-709.

20. Allmann, S. and Baldwin, I. T., Insects betray themselves in nature to predators by rapid isomerization of green leaf volatiles. Science, 2010, 329, 1075-1078.

21. Yukawa, J., Synchronization of gallers with host plant phenology. Popul. Ecol., 2000, 42, 105-113.

22. Kamala Jayanthi, P. D., Anjana, S., Rekha, A. and Mala, B. R. J., Eulophid seed borer, Anselmella kerrichi (Narayanan et al.; Hymenoptera), an emerging pest of jamun. Curr. Sci., 2019, 117, 922-924.

23. Kamala Jayanthi, P. D., Woodcock, C. M., Caulfield, J., Birkett, M. A. and Bruce, T. J., Isolation and identification of host cues from mango, Mangifera indica, that attract gravid female oriental fruit fly, Bactrocera dorsalis. J. Chem. Ecol., 2012, 38, 361-369.

24. Anfora, G., Tasin, M., De Cristofaro, A., Ioriatti, C. and Lucchi, A., Synthetic grape volatiles attract mated Lobesia botrana females in laboratory and field bioassays. J. Chem. Ecol., 2009, 35, 1054; https://doi:10.1007/s10886-009-9686-5.

25. Pettersson, J., Karunaratne, S., Ahmed, E. and Kumar, V., The cowpea aphid, Aphis craccivora, host plant odours and pheromones. Entomol. Exp. Appl., 1998, 88, 177-184.

26. Kovats, E. S., Gas chromatographic characterization of organic substances in the retention index system. Adv. Chromatogr., 1965, 1, 229-247.

27. Kamala Jayanthi, P. D., Raghava, T. and Kempraj, V., Functional diversity of infochemicals in agri-ecological networks. In Innovative Pest Management Approaches for the 21st Century (ed. Chakravarthy, A. K.), Springer, Singapore, 2020, pp. 187-192.

28. Dicke, M., Volatile spider-mite pheromone and host-plant kairomone, involved in spaced-out gregariousness in the spider mite Tetranychus urticae. Physiol. Entomol., 1986, 11, 251-262.

29. Dicke, M. and van Loon, J. J., Multitrophic effects of herbivoreinduced plant volatiles in an evolutionary context. Entomol. Exp. Appl., 2000, 97, 237-249.

30. Fatouros, N. E., Bukovinszkine'Kiss, G., Kalkers, L. A., Gamborena, R. S., Dicke. M. and Hilker, M., Oviposition-induced plant cues: do they arrest Trichogramma wasps during host location? Entomol. Exp. Appl., 2005, 115, 207-215.

31. Gatehouse, J. A., Plant resistance towards insect herbivores: a dynamic interaction. New Phytol., 2002, 156, 145-169.

32. Ohsaki, N. and Sato, Y., Food plant choice of Pieris butterflies as a trade-off between parasitoid avoidance and quality of plants. Ecology, 1994, 75, 59-68.

33. Fei, M., The importance of phenology in studies of plant-herbivoreparasitoid interactions, Ph.D. thesis, Wageningen University, Wageningen, NL, 2016, p. 170; ISBN 978-94-6257-655-1.2016.

ACKNOWLEDGEMENTS. We thank the Director, ICAR-Indian Institute of Horticultural Research, Bengaluru for providing research facilities. Technical support from T. S. Rajanna and J. Sagar is acknowledged. Financial support from the Indian Council of Agricultural Research, New Delhi through a National Fellow Project is acknowledged.

Received 16 January 2021; revised accepted 11 May 2021

doi: $10.18520 / \mathrm{cs} / \mathrm{v} 121 / \mathrm{i} 2 / 286-293$ 